\title{
Epidemiology of Gastrointestinal Cancers in the North of Iran: Results of Mazandaran Population-Based Cancer Registry
}

\author{
(D) Akbar HEDAYATIZADEH-OMRAN', (1) Majid YAGHOUBI-ASHRAFI', (D) Zainab QAZIZADEH', \\ (1) Razieh-Sadat MOUSAVI', (1) Ramin SHEKARRIZ', (1) Mohammad ESLAMI', Ehsan ZABOLI', \\ (1) Mahmood MOOSAZADEH ${ }^{2}$, (DGhasem JANBABAEI', (1) Mohsen AARABI', @Reza ALIZADEH-NAVAEI'
}

'Gastrointestinal Cancer Research Center, Non-communicable Diseases Institute, Mazandaran University of Medical Sciences, Sari-Iran ${ }^{2}$ Health Sciences Research center, Addiction Institute, Mazandaran University of Medical Sciences, Sari-Iran

\section{OBJECTIVE}

Although initial pathological studies indicate the high prevalence of gastrointestinal cancers in northern Iran, to our knowledge, no population-based cancer registry studies have been conducted on gastrointestinal cancers. Hence, the present research aimed to review the epidemiologic status of gastrointestinal cancers in northern Iran region using the population-based cancer registry data.

\section{METHODS}

This cross-sectional study was conducted on 4460 subjects in the Mazandaran Population-Based Cancer Registry, which is located in the North of Iran. Among gastrointestinal cancers diagnosed between 2014 and 2015, cancers with codes C15 to C26 were collected. Age-standardized incidence rate (ASR) (per 100,000 person-years) were calculated as standardized to the world standard population using the direct standardization method.

\section{RESULTS}

This study results showed that a total of 1318 (29.5\%) people were afflicted with gastrointestinal cancers in the studied area, the most prevalent of which included gastric cancer (44.2\%), colorectal cancer (27.2\%), and esophageal cancer (13.5\%). The mean age of the subjects was $66.15 \pm 14.7$, and 804 of them (61\%) were male. ASR in men and women was equal to 5.56 and 4.03 for esophageal cancer, 20.44 and 10.14 for gastric cancer, 1.61 and 1.4 for pancreatic cancer, and 10.86 and 8.74 for colorectal cancer and there was a significancant difference $(\mathrm{p}=0.008)$ for sex distribution in these cancers.

\section{CONCLUSION}

The findings obtained in this study suggested that gastrointestinal cancers account for a substantial percentage of cancers in northern Iran and that gastric cancer is the most prevalent type of gastrointestinal cancers in this region.

Keywords: Cancer registry; epidemiology; gastrointestinal cancers.

Copyright $\odot$ 2020, Turkish Society for Radiation Oncology

\section{Introduction}

Cancer is considered a major public health problem in developed countries, whereas $60 \%$ of the disease and
$70 \%$ of the deaths from cancer in 2008 occurred in the developing countries. [1,2]

According to the reports of Iran's Ministry of Health and Medical Education, cancers is the third leading
Dr. Reza ALIZADEH-NAVAEI

Gastrointestinal Cancer Research Center, Non-communicable Diseases Institute, Mazandaran University of Medical Sciences, Sari, Iran

E-mail: reza_nava@yahoo.com 
cause of death in this country after coronary artery diseases and accidents $[3,4]$ because unfortunately limited national programs are implemented in Iran in accordance with WHO guidelines for cancer screening and prevention.[5] The incidence of gastric cancer is declining in developed countries, such as the US and Canada,[6] whereas it is increasing in Asian and the developing countries.[6,7] The risk of affliction with gastric cancer is higher in the northern and northwest Iran, while it is moderate in the western and central provinces and low in the southern regions.[8]

The incidence of diseases in different regions may vary depending on genetic and dietary differences. [7] The results from the previous studies have highlighted the effects of behavioral and environmental factors on the development of gastric cancer around the world. The changes marked in the different geographic areas, on the one hand, and the highlighted differences in the frequency of environmental risk factors, on the other hand, provide an opportunity for research on the pathology of gastric cancer.[9]

Primary liver cancer is the sixth common cancer and the second leading cause of death from cancers in the world.[10] The highest incidence of liver cancer (50\%) has been observed in Eastern Asia, Southeast Asia, and Northern Africa.[10] The geographic regions of the world are divided into three categories according to the epidemiological distribution of hepatocellular carcinoma (HCC), including low, moderate, and high incidence, which occur in Southern Asia, Sub-Saharan Africa, Northern America, and Europe.[11] The difference in the geographical distribution of viral hepatitis $\mathrm{B}$ and $\mathrm{C}$, genetic differences, lifestyles, and the distribution of environmental carcinogens, such as aflatoxin, have caused discrepancies in the geographical distribution, population, and the number of hepatitis cases in the developed and developing countries.[11] As a country in the Middle East, Iran is an area with a low incidence of liver cancer.[12]

Colorectal cancer (CRC) is the third and second most common cancer in men and women, respectively, with 1.3 million new cases annually.[13] Considering the demographic patterns, the global burden of CRC is expected to increase by $60 \%$ and exceed 2.2 million new cases and 1.1 million deaths by 2030.[10] There are significant differences in the incidence and mortality rate among different ethnic and racial groups.[14] While the annual CRC incidence in Northern America and Europe is $30-50$ cases in every 100.000 people, this figure is equal to 37 cases in every 100.000 people in Middle Eastern countries. The cultural changes in the
Third World have led to a rapid rise in the incidence of CRC in these countries. [15,16]

Gallbladder cancer is one of the most common malignant cancers in the biliary system and the sixth common type of biliary-gastric cancers. [17] This type of cancer is currently difficult to be an early diagnosis and prognosis. The findings of a study revealed that the mean survival of patients with advanced gallbladder cancer is six months and its 5 -year survival rate is approximately $5 \%$.[18]

Esophageal cancer is the eighth most common cancer in the world and the sixth cause of cancer deaths. $[19,20]$ The term "Asian Esophageal Cancer Belt" extends from eastern Turkey through Iraq, Iran, and the southern part of the former Soviet Union (Kazakhstan, Turkmenistan, Uzbekistan, and Tajikistan) to Mongolia and western/northern China. The incidence of esophageal cancer is estimated to be 100 cases in every 100.000 people [21,22] and rapid progress are major features of this cancer,and diet plays an important role in its [21,23] pathogenesis. [24]

Pancreatic cancer is one of the main causes of cancer deaths in developed countries and one of the most common malignant neoplasms around the world. $[10,25]$ Based on GLOBOCAN 2012 estimates, pancreatic cancer causes more than 331.000 deaths annually and is ranked seventh among the causes of cancer-related deaths in both genders. Approximately 338.000 people were diagnosed with pancreatic cancer in 2012, making it the 11th most common type of cancer.[10] The 5-year survival rate for pancreatic cancer has been estimated to be less than 5\%.[10,26] Since there is no screening method for pancreatic cancer, early prevention is of special importance for patients. Hence, it is necessary to achieve a better understand-ing of the epidemiology and identify the risk factors for pancreatic cancer.[27]

With a total area of $23.800 \mathrm{~km}^{2}$, Mazandaran Province is located in northern Iran in the vicinity of Alborz Mountains (Fig. 1).[28] Drinking water used by people in this area is rich in minerals.[29] Mazandaran Province is located on the gastrointestinal cancer belt and even Ramsar, one of its towns, is one of the most notorious regions of the world because of high levels of radium in its rocks, soil, and underground waters, exposing the inhabitants to excessive levels of ICRP-60 radium (20 mSv y-1).[30]

Although initial pathological studies indicate the high prevalence of gastrointestinal cancers in this region of Iran, a few population-based cancer registry studies have been conducted on gastrointestinal 
cancers. Hence, the present research aims to review the epidemiologic status of gastrointestinal cancers in this region using the population-based cancer registry data.

\section{Materials and Methods}

This is a cross-sectional study and population-based survey on 4460 subjects in the Mazandaran Population-Based Cancer Registry (MazPCR) office, which is located in Mazandaran province in the North of Iran. Cancer cases were classified according to International Classification of Diseases for Oncology, the third edition (ICD-O-III). The data for this project on gastrointestinal cancers diagnosed between 2014-2015 (one solar year) were collected based on related checklists MazPCR office of Mazandaran University of Medical Sciences include; C15 (Esophagus), C16 (Stomach), C17 (Small intestine), C18 (Colon), C19 (Rectosigmoid junction), C20 (Rectum), C21 (Anus and anal canal), C22(Liver and intrahepatic bile ducts), C23 (Gallbladder), C24 (Other and unspecified parts of biliary tract), C25 (Pancreas) and C26 (other and ill-defined digestive organs) codes. In this registry, data were obtained from all hospitals, pathology laboratories, diagnostic radiology clinics, outpatient public and private clinics, main insurer organizations in Mazandaran Province and Health Center of Mazandaran University of Medical Sciences for cancer-related deaths.

Age-standardized incidence rates (ASR) (per 100,000 person-years) were calculated as standardized to the world standard population by the direct standardization method for each cancer by excel software. ASR were calculated for 5-year age groups (0-4, 5-9, ..., 80-84, 285) and sex. The data were analyzed using SPSS 16 statistical software and Chi-square, t-test and Anova tests. A p-value of less than 0.05 was considered to be statistically significant. This study was approved by the Ethical Committee of Mazandaran University of Medical Sciences.

\section{Results}

Out of the 4460 newly diagnosed patients with cancer in the studied year, 1318 patients $(29.5 \%)$ were afflicted with gastrointestinal cancers, 804 of whom (61\%) were male and 514 of them (39\%) were female. The total crude rate of gastrointestinal cancers in the studied region was obtained to be 47.9 in every 100.000 people. The highest crude rate of gastrointestinal cancers was related to Savadkuh $(\mathrm{ASR}=100.2)$ and Ram-

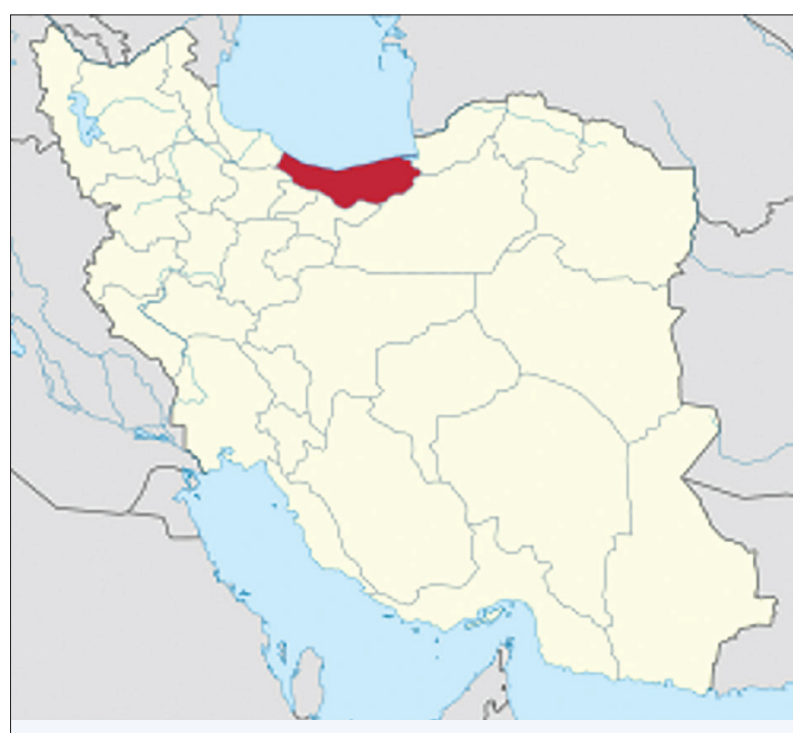

Fig. 1. Map of Iran and Mazandaran province.

sar (ASR=60). In addition, the lowest crude rate was observed in Abbasabad (ASR=13.2). The mean age of the subjects was $66.15 \pm 14.7$. The age distribution of the two genders is presented in Figure 2. The most frequent age group was 60-64 (15.3\%) for women and 80$84(13.6 \%)$ for men. Overall, the mean age of women and men with gastrointestinal cancers was equal to $65.1 \pm 15.1$ and $66.7 \pm 14.5$, respectively, which suggested no significant difference $(\mathrm{p}=0.054)$.

Out of the studied patients, 490 (52.2\%) were living in urban areas and 448 of them $(47.8 \%)$ were living in rural areas (place of residence of 380 patients was unknown). The cancer diagnosis was based on pathological examinations, death certificate only (DCO), and

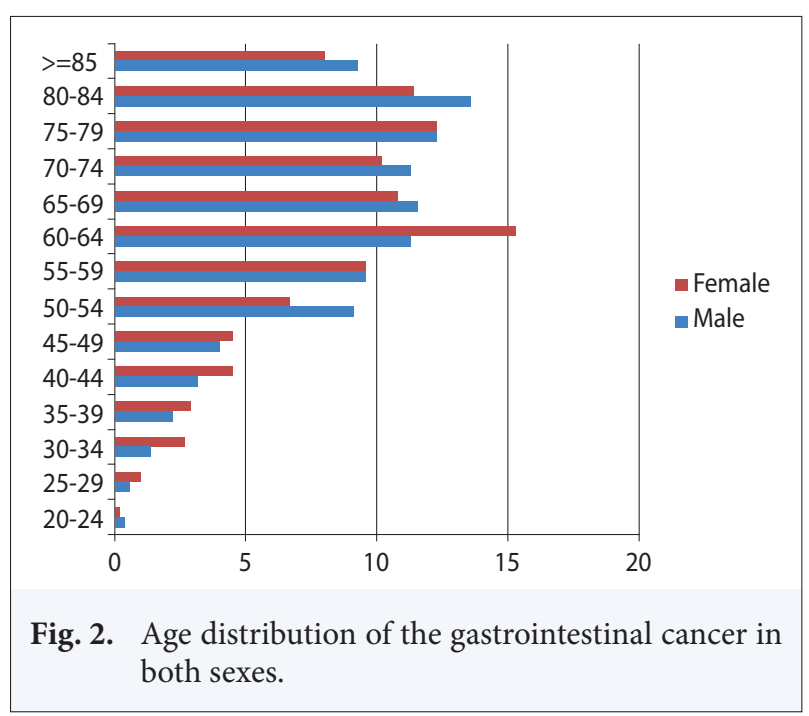


clinical examinations in 732 (55.5\%), 391 (29.7\%), and 195 (14.8\%) patients, respectively.

The most prevalent cancers included gastric cancer (44.2\%), colorectal cancer (27.2\%), and esophageal cancer (13.5\%) (Table 1). The ASR distribution of cancers in different age groups of both genders is presented in Table 2. ASR in men and women was equal to 5.56 and 4.03 for esophageal cancer, 20.44 and 10.14 for gastric cancer, 1.61 and 1.4 for pancreatic cancer, and 10.86 and 8.74 for colorectal cancer. The mean age of patients with colorectal cancer was significantly lower than the other patients $(p=0.000)$. There was a significant difference between men and women in terms of affliction with gastrointestinal cancers, as the number of men afflicted with esophageal, gastric, and colorectal cancers was more than women ( $\mathrm{p}=0.008)$. The frequency of residence in rural areas was higher in esophageal, colorectal, and pancreatic cancers, whereas most patients with gastric cancer were inhabitants of urban areas $(\mathrm{p}=0.000)$. Among 732 patients whose cancer diagnosis were based on pathological examinations, the findings obtained in this study showed that most cases of esophageal, gastric, and colorectal cancers were of moderate grade (Table 3 ).

\section{Discussion}

In the present study, the most prevalent gastrointestinal cancer was gastric cancer with an ASR of 20.44 and 10.14 for men and women, respectively. A study conducted by Somi et al.[31] on gastrointestinal cancers in Ardabil Province showed that gastric cancer was the most prevalent type of cancer with an ASR of 23.1 and 7.69 for men and women, respectively.This is somewhat
Table 1. Frequency of different type of gastrointestinal cancer in the north of Iran

\begin{tabular}{lc} 
Type of cancer & Frequency (\%) \\
\hline Stomach & $582(44.2)$ \\
Colorectal & $358(27.2)$ \\
Esophagus & $178(13.5)$ \\
Pancreas & $57(4.3)$ \\
Small intestine & $35(2.7)$ \\
Liver and intrahepatic bile ducts & $12(0.9)$ \\
Gallbladder & $8(0.6)$ \\
Anus and anal canal & $3(0.2)$ \\
Other and unspecified parts of biliary tract & $10(0.8)$ \\
Other and ill-defined digestive organs & $75(5.7)$ \\
Total & $1318(100)$ \\
\hline
\end{tabular}

consistent with the results of this study. Sierra et al.[32] (2016) reported that the ASR of gastric cancer in Central and South America is equal to 19.2-29.1 for men and 9.7-15.1 for women.However, the prevalence of gastric cancer is very low in some areas like Saudi Arabia, as it is not classified among the 10 common cancers.[33]

In the present study, the ASR of esophageal cancer was equal to 5.56 for men and 4.03 for women. These figures were reported to be 9.69 for men and 7.35 for women by Somi et al. [31], a bit more than those of the present study. Zhao et al.[34] (2008) showed that the ASR of esophageal cancer is equal to 12.4 for both men and women in China.In a study conducted in four countries in West Africa, this figure for men and women was equal to 47.2 and 30.3 in Blantyre, 33.4 and 25.3 in Harare, 36.7 and 24.8 in Kampala, and 22.6 and 21.6 in Nairobi, [35] which are more than those obtained in the present study.

Table 3. The relation between different types of gastrointestinal cancer with age, sex, district and cancer differentiation

\begin{tabular}{|c|c|c|c|c|c|}
\hline & $\begin{array}{l}\text { Esophagus } \\
\qquad(n=178)\end{array}$ & $\begin{array}{l}\text { Stomach } \\
(n=582)\end{array}$ & $\begin{array}{l}\text { Colorectal } \\
(n=358\end{array}$ & $\begin{array}{c}\text { Pancreas } \\
(n=57)\end{array}$ & P-value \\
\hline \multicolumn{6}{|l|}{ Age } \\
\hline mean $\pm S D$ & $69.2 \pm 14.9$ & $67.3 \pm 14.5$ & $62.5 \pm 15.8$ & $68 \pm 12$ & 0.000 \\
\hline \multicolumn{6}{|l|}{ Sex } \\
\hline Male; n (\%) & $105(59)$ & $383(65.8)$ & $201(56.1)$ & $29(50.9)$ & 0.008 \\
\hline Female; n (\%) & $73(41)$ & $199(34.2)$ & $157(43.9)$ & $28(49.1)$ & \\
\hline \multicolumn{6}{|l|}{ District } \\
\hline Urban; n (\%) & $78(58.2)$ & $178(42.1)$ & $162(62.8)$ & $24(61.5)$ & 0.000 \\
\hline Rural; n (\%) & $56(41.8)$ & $245(57.9)$ & $96(37.2)$ & $15(38.5)$ & \\
\hline \multicolumn{6}{|c|}{ Grade (differentiation) } \\
\hline Well; n (\%) & $14(25.5)$ & $16(13.9)$ & $42(38.9)$ & - & 0.000 \\
\hline Moderate; n (\%) & $25(45.5)$ & $51(44.3)$ & $57(52.8)$ & $2(40)$ & \\
\hline Poor; n (\%) & $16(29.1)$ & $48(41.7)$ & $9(8.3)$ & $3(60)$ & \\
\hline
\end{tabular}




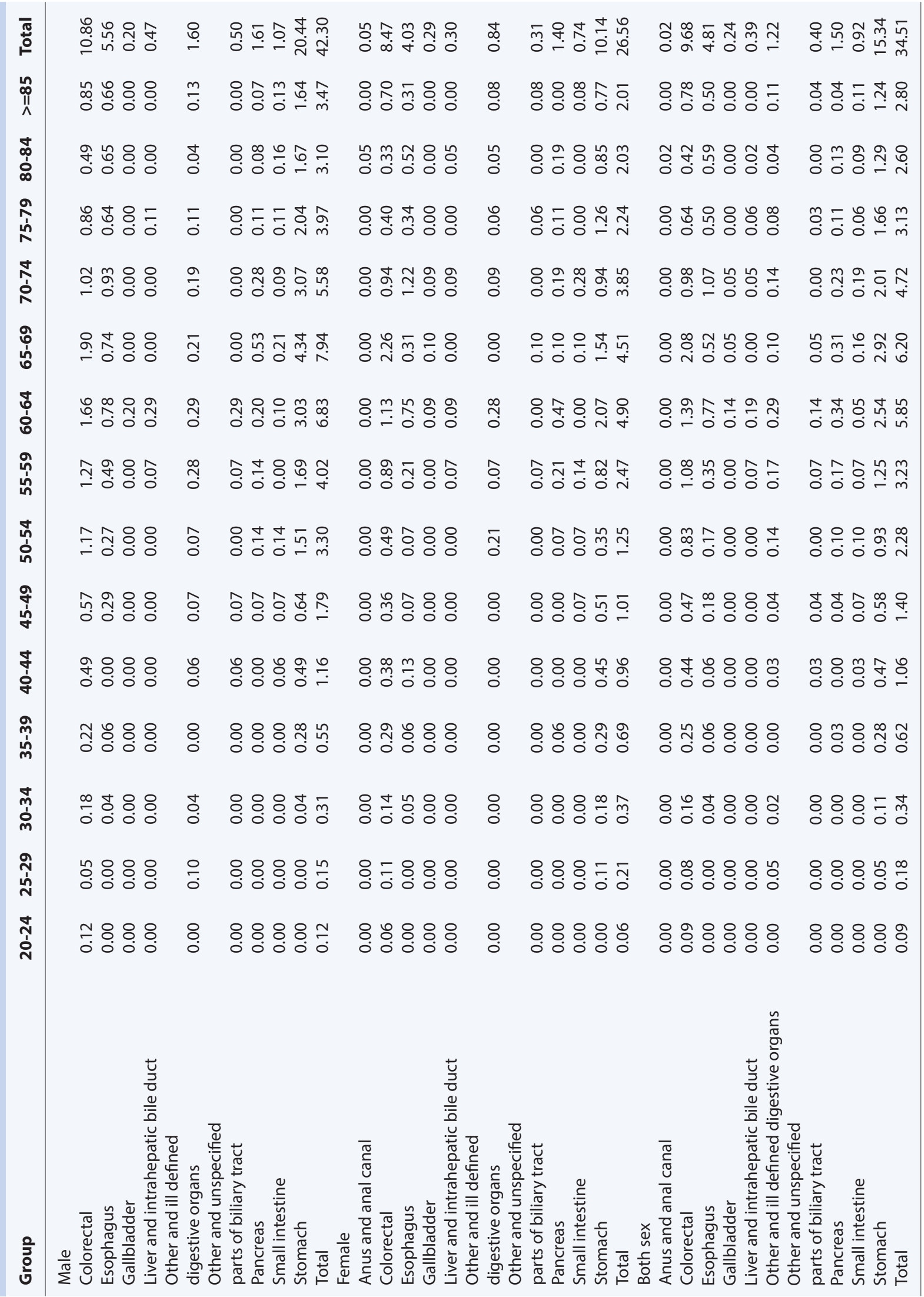


The study results also showed that the ASR of pancreatic cancer is 1.61 for men and 1.4 for women. This figure was reported to be equal to 0.2 for both genders by Somi et al.[31], which is less than those of the present study. In contrast, in a study conducted by Chen in China in 2011, this figure was obtained to be 5.09 for both genders. [36]

One of the criteria to assess the quality of the population-based cancer registry is the diagnosis type.[37] In the present study, the cancer diagnosis was based on pathological examinations, DCO, and clinical examinations in 732 (55.5\%), 391 (29.7\%), and 195 (14.8\%) patients, respectively. In a study on population-based cancer registries in Japan, the 25 rate was equal to 13.214.1\%.[38] However, this ODC figure was obtained at $0.9 \%$ in another study less conducted in Norway in $2009,[39]$ which is much than that of the present study and the latter. Although the DCO rate was high in the present study, it is not alarming for the populationbased cancer registry in the first year.

Overall, the prevalence of gastrointestinal cancers in men was 1.5 times higher than women. In a pathology-based cancer registry study conducted by Somi $e t$ al.[31] in Ardabil, the prevalence of gastrointestinal cancers in men was 1.7 times higher than that of women,which is consistent with the findings of the present study. Ardabil Province, also located in the Northen strip of Iran, like Mazandaran, is one of the three provinces of Iran where gastrointestinal cancers are highly prevalent.

The highest crude rate of gastrointestinal cancers was related to Savadkuh and Ramsar. Savadkuh is one of the highland towns in Mazandaran Province and Ramsar is also a region with high natural radiation, where people are exposed to excessive levels of radium. Garrido showed that living in highlands is associated with a higher risk of cancers, such as gastric and colorectal cancers. [40] The findings of Akan et al.[41] (2014) showed a significant correlation between high natural radiation and the incidence of gastric and esophageal cancers.

One of the strengths of the present study is that it was the first population-based cancer registry in one of the regions of Iran with a high prevalence of gastrointestinal cancers. On the other hand, one of the limitations of this study was the high level of DCO, which is expected to reduce in future years through the expansion of the cancer registry. According to the study results, the survival rate of patients with cancers is recommended to be included in the cancer registry.

\section{Conclusion}

The study results suggested that gastrointestinal cancers account for a substantial percentage of cancers in northern Iran. It was found that gastric cancer is the most prevalent type of gastrointestinal cancers in this region.

Peer-review: Externally peer-reviewed.

Conflict of Interest: All authors declared no conflict of interest.

Ethics Committee Approval: This study was approved by the Ethical Committee of Mazandaran University of Medical Sciences.

Financial Support: This study was supported by Mazandaran University of Medical Sciences with grant number 952677.

Authorship contributions: Concept - R.A.N., A.H.O., G.H.J., M.A.; Design - R.A.N.; Materials - M.Y.A., Z.G.H., R.S.M., R.S.H., M.E., E.Z.; Data collection and/or processing - M.Y.A., Z.G.H., R.S.M., R.S.H., M.E., E.Z.; Data analysis and/or interpretation - R.A.N., Z.G.H.; Writing - R.A.N.; Critical review - A.H.O., M.Y.A., Z.G.H., R.S.M., R.S.H., M.E., E.Z., M.M., G.H.J., M.A.

\section{References}

1. Bray F, Jemal A, Grey N, Ferlay J, Forman D. Global cancer transitions according to the Human Development Index (2008-2030): a population-based study. Lancet Oncol 2012;13(8):790-801.

2. Lee SG, Kim B, Yook JH, Oh ST, Lee I, Song K. TNF/ LTA polymorphisms and risk for gastric cancer/ duodenal ulcer in the Korean population. Cytokine 2004;28(2):75-82.

3. Naghavi M, Abolhassani F, Pourmalek F, Lakeh M, Jafari N, Vaseghi S, et al. The burden of disease and injury in Iran 2003. Popul Health Metr 2009;7:9.

4. Mousavi SM, Gouya MM, Ramazani R, Davanlou M, Hajsadeghi N, Seddighi Z. Cancer incidence and mortality in Iran. Ann Oncol. 2009;20(3):556-563.

5. Mousavi SM, Alamolhoda AA, Gouya MM, Lickiss N. Implementation of Comprehensive National Cancer Control Program in Iran: an experience in a developing country. Ann Oncol 2008;19(2):398-400.

6. Bertuccio P, Chatenoud L, Levi F, Praud D, Ferlay J, Negri E, et al. Recent patterns in gastric cancer: a global overview. Int J Cancer 2009;125(3):666-73.

7. Hartgrink HH, Jansen EP, van Grieken NC, van de Velde CJ. Gastric cancer. Lancet 2009;374(9688):477-90.

8. Sadjadi A, Malekzadeh R, Derakhshan MH, Sepehr A, Nouraie M, Sotoudeh M, et al. Cancer occurrence in 
Ardabil: results of a population-based cancer registry from Iran. Int J Cancer 2003;107(1):113-8.

9. Malekzadeh R, Derakhshan MH, Malekzadeh Z. Gastric cancer in Iran: epidemiology and risk factors. Arch Iran Med 2009;12(6):576-83.

10. Ferlay J, Soerjomataram I, Dikshit R, Eser S, Mathers C, Rebelo M, et al. Cancer incidence and mortality worldwide: sources, methods and major patterns in GLOBOCAN 2012. Int J Cancer 2015;136(5):E359-86.

11. Lafaro KJ, Demirjian AN, Pawlik TM. Epidemiology of hepatocellular carcinoma. Surg Oncol Clin N Am 2015;24(1):1-17.

12. Nordenstedt H, White DL, El-Serag HB. The changing pattern of epidemiology in hepatocellular carcinoma. Dig Liver Dis 2010;42 Suppl 3(Suppl 3):S206-14.

13. Allemani C, Weir HK, Carreira H, Harewood R, Spika D, Wang XS, et al. Global surveillance of cancer survival 1995-2009: analysis of individual data for 25,676,887 patients from 279 population-based registries in 67 countries (CONCORD-2). Lancet 2015;385(9972):977-1010.

14. Haghdoust AA, Chamani G, Zarei MR, Rad M, Hashemipour M, Marzban M. Low incidence of colorectal cancer in Kerman province, Iran. Iranian journal of cancer prevention. 2011; 4(1): 33-7.

15. Saberi-Firoozi M, Kamali D, Yousefi M, Mehrabani D, Khademolhosseini F, Heydari S, et al. Clinical characteristics of colorectal cancer in Southern Iran, 2005. Iran Red Crescent Med J 2007;9(4):209-11.

16. Abdifard E, Ghaderi S, Hosseini S, Heidari M. Incidence trends of colorectal cancer in the West of Iran during 2000-2005. Asian Pac J Cancer Prev 2013;14(3):1807-11.

17. Wistuba II, Gazdar AF. Gallbladder cancer: lessons from a rare tumour. Nat Rev Cancer. 2004 Sep;4(9):695-706.

18. Hundal R, Shaffer EA. Gallbladder cancer: epidemiology and outcome. Clin Epidemiol 2014;6:99-109.

19. Pennathur A, Gibson MK, Jobe BA, Luketich JD. Oesophageal carcinoma. Lancet. 2013 Feb 2;381(9864):400-12.

20. Umar SB, Fleischer DE. Esophageal cancer: epidemiology, pathogenesis and prevention. Nat Clin Pract Gastroenterol Hepatol 2008;5(9):517-26.

21.Zhang Y. Epidemiology of esophageal cancer. World J Gastroenterol 2013;19(34):5598-606.

22. Chong VH, Telisinghe PU, Chong CF. Esophageal Cancer in Brunei Darussalam over a three Decade Period: an Epidemiologic Study of Trends and Differences between Genders and Racial Groups. Asian Pac J Cancer Prev 2015;16(9):4123-6.

23. Mao WM, Zheng WH, Ling ZQ. Epidemiologic risk factors for esophageal cancer development. Asian Pac J Cancer Prev 2011;12(10):2461-6.
24. Wu M, Zhao JK, Hu XS, Wang PH, Qin Y, Lu YC, et al. Association of smoking, alcohol drinking and dietary factors with esophageal cancer in high- and low-risk areas of Jiangsu Province, China. World J Gastroenterol 2006;12(11):1686-93.

25.Howlader N, Noone AM, Krapcho M, Miller D, Bishop K, Altekruse SF, et al. SEER Cancer Statistics Review, 1975-2013. National Cancer Institute. Available at: https://seer.cancer.gov/archive/csr/1975_2013/ Accessed Aug 26, 2020.

26. Hidalgo M, Cascinu S, Kleeff J, Labianca R, Löhr JM, Neoptolemos J, et al. Addressing the challenges of pancreatic cancer: future directions for improving outcomes. Pancreatology 2015;15(1):8-18.

27. Pourhoseingholi MA, Ashtari S, Hajizadeh N, Fazeli Z, Zali MR. Systematic review of pancreatic cancer epidemiology in Asia-Pacific Region: major patterns in GLOBACON 2012. Gastroenterol Hepatol Bed Bench. 2017;10(4): 245-57.

28. Mohebbi M, Mahmoodi M, Wolfe R, Nourijelyani K, Mohammad K, Zeraati H, et al. Geographical spread of gastrointestinal tract cancer incidence in the Caspian Sea region of Iran: spatial analysis of cancer registry data. BMC Cancer 2008;8:137.

29. Yazdani-Charati J, Janbabaei G, Etemadinejad S, Sadeghi S, Haghighi F. Survival of patients with stomach adenocarcinoma in North of Iran. Gastroenterol Hepatol Bed Bench 2014;7(4):211-7.

30. Mortazavi S, Niroomand-Rad A, Roshan-Shomal P, Razavi-Toosi S, Mossayeb-Zadeh M, Moghadam M. Does short-term exposure to elevated levels of natural gamma radiation in Ramsar cause oxidative stress? Int J Appl Basic Med Res 2014;4(2):72-6.

31. Somi MH, Golzari M, Farhang S, Naghashi S, Abdollahi L. Gastrointestinal cancer incidence in East Azerbaijan, Iran: update on 5 year incidence and trends. Asian Pac J Cancer Prev 2014;15(9):3945-9.

32. Sierra MS, Cueva P, Bravo LE, Forman D. Stomach cancer burden in Central and South America. Cancer Epidemiol 2016;44 Suppl 1:62-73.

33. Bazarbashi S, Al Eid H, Minguet J. Cancer Incidence in Saudi Arabia: 2012 Data from the Saudi Cancer Registry. Asian Pac J Cancer Prev 2017;18(9):2437-44.

34. Zhao J, He YT, Zheng RS, Zhang SW, Chen WQ. Analysis of esophageal cancer time trends in China, 19892008. Asian Pac J Cancer Prev 2012;13(9):4613-7.

35. Cheng ML, Zhang L, Borok M, Chokunonga E, Dzamamala C, Korir A, et al. The incidence of oesophageal cancer in Eastern Africa: identification of a new geographic hot spot? Cancer Epidemiol 2015;39(2):143-9.

36. Chen W, Zheng R, Zeng H, Zhang S. The updated incidences and mortalities of major cancers in China, 2011. Chin J Cancer 2015;34(11):502-7.

37. Bray F, Parkin DM. Evaluation of data quality in 
the cancer registry: principles and methods. Part I: comparability, validity and timeliness. Eur J Cancer 2009;45(5):747-55.

38. Matsuda A, Matsuda T, Shibata A, Katanoda K, Sobue $\mathrm{T}$, Nishimoto $\mathrm{H}$, et al. Cancer incidence and incidence rates in Japan in 2008: a study of 25 populationbased cancer registries for the Monitoring of Cancer Incidence in Japan (MCIJ) project. Jpn J Clin Oncol 2014;44(4):388-96.

39. Larsen IK, Småstuen M, Johannesen TB, Langmark F, Parkin DM, Bray F, et al. Data quality at the Cancer
Registry of Norway: an overview of comparability, completeness, validity and timeliness. Eur J Cancer 2009;45(7):1218-31.

40. Garrido DI, Garrido SM. Cancer risk associated with living at high altitude in Ecuadorian population from 2005 to 2014. Clujul Med 2018;91(2):188-196.

41. Akan Z, Baskurt B, Asliyuksek H, Kam E, Yilmaz A, Yuksel $\mathrm{MB}$, et al. Environmental radioactivity and high incidence rates of stomach and esophagus cancer in the Van Lake region: a causal relationship? Asian Pac J Cancer Prev 2014;15(1):375-80. 